\title{
Hypoglycemic Accuracy and Improved Low Glucose Alerts of the Latest Dexcom G4 Platinum Continuous Glucose Monitoring System
}

\author{
Thomas A. Peyser, PhD, Katherine Nakamura, $\mathrm{PhD}_{1}^{2}$ David Price, MD, \\ Lucas C. Bohnett, MS, ${ }^{2}$ Irl B. Hirsch, MD, and Andrew Balo, BS ${ }^{2}$
}

\begin{abstract}
Objective: Accuracy of continuous glucose monitoring (CGM) devices in hypoglycemia has been a widely reported shortcoming of this technology. We report the accuracy in hypoglycemia of a new version of the Dexcom (San Diego, CA) G4 Platinum CGM system (software 505) and present results regarding the optimum setting of CGM hypoglycemic alerts.

Materials and Methods: CGM values were compared with YSI analyzer (YSI Life Sciences, Yellow Springs, $\mathrm{OH})$ measurements every $15 \mathrm{~min}$. We reviewed the accuracy of the CGM system in the hypoglycemic range using standard metrics. We analyzed the time required for the CGM system to detect biochemical hypoglycemia $(70 \mathrm{mg} / \mathrm{dL})$ compared with the YSI with alert settings at $70 \mathrm{mg} / \mathrm{dL}$ and $80 \mathrm{mg} / \mathrm{dL}$. We also analyzed the time between the YSI value crossing $55 \mathrm{mg} / \mathrm{dL}$, defined as the threshold for cognitive impairment due to hypoglycemia, and when the CGM system alerted for hypoglycemia.

Results: The mean absolute difference for a glucose level of less than $70 \mathrm{mg} / \mathrm{dL}$ was $6 \mathrm{mg} / \mathrm{dL}$. Ninety-six percent of CGM values were within $20 \mathrm{mg} / \mathrm{dL}$ of the YSI values between 40 and $80 \mathrm{mg} / \mathrm{dL}$. When the CGM hypoglycemic alert was set at $80 \mathrm{mg} / \mathrm{dL}$, the device provided an alert for biochemical hypoglycemia within $10 \mathrm{~min}$ in $95 \%$ of instances and at least a 10-min advance warning before the cognitive impairment threshold in $91 \%$ of instances in the study. Conclusions: Use of an $80 \mathrm{mg} / \mathrm{dL}$ threshold setting for hypoglycemic alerts on the G4 Platinum (software 505) may provide patients with timely warning of hypoglycemia before the onset of cognitive impairment, enabling them to treat themselves for hypoglycemia with fast-acting carbohydrates and prevent neuroglycopenia associated with very low glucose levels.
\end{abstract}

\section{Introduction}

T HE LANDMARK JDRF Continuous Glucose Monitoring (CGM) Study found that sustained use of CGM improved glycemic control in patients with type 1 diabetes. ${ }^{1}$ Adults and children who used the sensor on average 6 days/ week or more experienced a $0.5 \%$ decrease in hemoglobin A1c over the duration of the study. ${ }^{2,3}$ There was no difference observed, however, in the study in the frequency or duration of biochemical hypoglycemia or severe hypoglycemia. Battelino et al. ${ }^{4}$ found that use of real-time CGM decreased the duration of hypoglycemia, but they did not observe a statistically significant reduction in the incidence of severe hypoglycemia. A recent review by Little et al. ${ }^{5}$ noted that CGM was associated with lowered hemoglobin A1c without increased incidence of hypoglycemia, but CGM did not prevent the incidence of both biochemical and severe hypoglycemia. Finally, Zijlstra et al. ${ }^{6}$ reported that the CGM device used in their study on alarms and alerts "...is least accurate in the hypoglycaemic range leading to a failure to detect more than half of the true hypoglycaemic events. Furthermore, more than half of the alarms that were sounded to warn patients for hypoglycaemia were false."

\footnotetext{
${ }^{1}$ Menlo Park, California.

${ }^{2}$ Dexcom, Inc., San Diego, California.

${ }^{3}$ University of Washington, Seattle, Washington.

Data from this study are from the study registered at ClinicalTrials.gov with clinical trial registration number NCT02087995.

(c) The Author(s) 2015; Published by Mary Ann Liebert, Inc. This Open Access article is distributed under the terms of the Creative Commons Attribution Noncommercial License (http://creativecommons.org/licenses/by-nc/4.0/) which permits any noncommercial use, distribution, and reproduction in any medium, provided the original author(s) and the source are credited.
} 
The poor accuracy of previous generations of CGM devices in the hypoglycemic range may be an important factor in explaining the lack of evidence for the benefit of CGM in reducing the incidence of hypoglycemia. The recent American Diabetes Association (ADA) and Endocrine Society Workgroup on Hypoglycemia report discussed the use of CGM in patients at risk for hypoglycemia: "Recent technological developments have provided patients with new tools for glucose monitoring. Real-time CGM, by virtue of its ability to display the direction and rate of change, provides helpful information to the wearer leading to proactive measures to avoid hypoglycemia, e.g., when to think about having a snack or suspending insulin delivery on a pump. The CGM's audible and/or vibratory alarms may be particularly helpful in avoiding severe hypoglycemia at night and restoring hypoglycemic awareness." 7 The ADA and Endocrine Society Workgroup on Hypoglycemia explicitly identified the potential problem associated with poor CGM accuracy in the hypoglycemic range: "Retrospective and real-time CGMs represent an evolving technology that has made considerable progress in overall accuracy. However, the accuracy of CGMs in the hypoglycemic range is poor.,"7

The ADA has recommended the use of $70 \mathrm{mg} / \mathrm{dL}$ for hypoglycemic alerts in order to give the patient adequate time to treat an impending hypoglycemic event and prevent a further decrease of the blood glucose level into more pronounced hypoglycemia. ${ }^{8}$ As noted by Cryer ${ }^{9}$ in an article on the appropriate glucose level for hypoglycemic alerts, $70 \mathrm{mg} / \mathrm{dL}$ approximates the lower end of fasting glucose and the threshold for the counterregulatory response in individuals without diabetes. In particular, he noted that "the recommended glucose alert level of $70 \mathrm{mg} / \mathrm{dL}$...generally gives the patient time to take action to prevent a clinical hypoglycemic episode." "9 A guidance document on CGM published by the Clinical and Laboratory Standards Institute noted the clinical motivation for the characterization of CGM alerts with following question on behalf of patients using these devices: "If my blood glucose levels go below my hypoglycemic alert threshold..., what is the likelihood that the CGM will alert me to the situation?",10

The goal of a CGM hypoglycemia alert is to detect a hypoglycemic state before it progresses to a level of neuroglycopenia and cognitive impairment that would jeopardize the patient's ability to take action and recover without assistance from others. The clinical threshold for cognitive impairment may vary from individual to individual, depending on a variety of factors. ${ }^{11}$ Nonetheless, there is a general consensus that neuroglycopenic symptoms are commonly observed at approximately $55 \mathrm{mg} / \mathrm{dL} .{ }^{12}$ Blood glucose measurements of less than $55 \mathrm{mg} / \mathrm{dL}$ are associated with a high risk of severe hypoglycemia requiring the need for assistance from others, cognitive impairment, seizures, or comas. ${ }^{13}$ In this article, we examine the time between the CGM hypoglycemic alert and the actual blood glucose value crossing the threshold for biochemical hypoglycemia, defined as $70 \mathrm{mg} / \mathrm{dL}$. We also examine the time between the CGM hypoglycemic alert and the actual blood glucose value crossing the threshold for cognitive impairment due to hypoglycemia, defined as $55 \mathrm{mg} / \mathrm{dL}$.

The use of $70 \mathrm{mg} / \mathrm{dL}$ as the recommended threshold for hypoglycemic alerts is based on measurement of blood glucose and not interstitial fluid glucose as measured by CGM devices. The physiological delay between blood glucose and interstitial glucose may impact the time for the CGM system to indicate the presence of biochemical hypoglycemia. Although recent radiotracer studies have shown that the true physiological lag between blood glucose and interstitial fluid glucose is small, the lag time is not zero. ${ }^{14}$ Interstitial fluid glucose may lag blood glucose by up to $10 \mathrm{~min} .{ }^{15}$ In cases of rapidly falling blood glucose levels, CGM devices with threshold alerts set at $70 \mathrm{mg} / \mathrm{dL}$ may not alert the patient for biochemical hypoglycemia until many minutes after the blood glucose value has crossed the threshold. In this article, we examined whether using a higher CGM alert threshold for hypoglycemia $(80 \mathrm{mg} / \mathrm{dL}$ instead of $70 \mathrm{mg} / \mathrm{dL})$ could mitigate the effect of interstitial fluid glucose delay relative to blood glucose during periods of rapidly falling glucose levels.

\section{Materials and Methods}

Data for the analysis included in this article were obtained from a pivotal study submitted for regulatory approval of the Dexcom (San Diego, CA) G4 Platinum (software 505) CGM system with a modified algorithm for converting the raw electrochemical sensor signal into calibrated glucose values. Details of the new algorithm have been reported previously as applied retrospectively to the original G4 Platinum pivotal study data. ${ }^{16}$ In this article, the new algorithm was applied prospectively in an open-label, single-arm, multicenter, pivotal study. Study design, demographics, and overall results of the study for the new algorithm have been reported by Bailey et al. $^{17}$

Following screening, 51 subjects with diabetes mellitus were enrolled at three clinical centers in the United States. The G4 Platinum (software 505) reported by Bailey et al. ${ }^{17}$ and discussed further here was approved by the U.S. Food and Drug Administration in November 2014.

All subjects wore one sensor for up to 7 days. Subjects participated in one clinic session lasting up to $12 \mathrm{~h}$ in order to obtain blood glucose measurements with a laboratory reference to assess the CGM accuracy. Venous samples were drawn approximately once every $15 \pm 5 \mathrm{~min}$ to allow for measurement of blood glucose level using a YSI 2300 STAT Plus ${ }^{\mathrm{TM}}$ glucose analyzer (YSI Life Sciences, Yellow Springs, $\mathrm{OH})$. Glucose was safely manipulated to obtain values in the low glucose range and across the entire glycemic spectrum. Subjects and clinicians were blinded to CGM values and alerts during the clinic session. All subjects provided witnessed, written informed consent prior to enrollment.

\section{Analysis methods}

We report on the accuracy of the new version of the G4 Platinum CGM in the hypoglycemic range using standard methods of analysis such as the mean absolute difference and the percentage of points within $( \pm) 10 \mathrm{mg} / \mathrm{dL}, 15 \mathrm{mg} / \mathrm{dL}$, and $20 \mathrm{mg} / \mathrm{dL}$ of the reference value in the hypoglycemic range (40-80 mg/dL). Density bias or Bland-Altman plots are an accepted method for assessing performance of a novel measurement technology compared with an established reference measurement method. ${ }^{18}$ In CGM, the $y$-axis of the BlandAltman plot is typically the difference between the sensor and the reference, and the $x$-axis is the reference measurement alone. In order to assess whether the accuracy of the new CGM system improved relative to previous generations of 
CGM devices, we compare Bland-Altman plots in the hypoglycemic range for the original G4 Platinum and the new G4 Platinum (software 505).

We examined the impact of setting the CGM hypoglycemic alert at either $70 \mathrm{mg} / \mathrm{dL}$ or $80 \mathrm{mg} / \mathrm{dL}$ on two new metrics for assessing the clinical utility of CGM to prevent hypoglycemia. The first new metric is the biochemical hypoglycemia alert time (BHAT), defined as the time for the CGM system to alert to indicate hypoglycemia compared with the estimated time the YSI value crossed the $70 \mathrm{mg} / \mathrm{dL}$ threshold. The second new metric is the hypoglycemic cognitive impairment threshold alert (HCITA) time, defined as the time for the CGM system to alert compared with the estimated time that the YSI value crossed $55 \mathrm{mg} / \mathrm{dL}$. The estimated time for the YSI value to cross a threshold was obtained from a linear interpolation between the two sequential decreasing YSI values on each side of the threshold value. The threshold for biochemical hypoglycemia and the threshold for hypoglycemic cognitive impairment are shown graphically in Figure 1.

In our analysis, we provide data on the difference in time between when the YSI measurements were estimated to cross $70 \mathrm{mg} / \mathrm{dL}$ and the time the CGM system alerted for hypoglycemia for each episode of hypoglycemia observed during the in-clinic portion of the study as determined by YSI measurements. The data are plotted in a cumulative distribution function showing the percentage of two different CGM hypoglycemia alert settings compared with the time for the estimated YSI value crossing of the biochemical hypoglycemia threshold. Cumulative distribution functions are also used to show the percentage of two different CGM hypoglycemia alert settings compared with the time for the estimated YSI value crossing of the threshold for cognitive impairment.
We analyzed missed hypoglycemic alerts (or false-negatives) by defining a missed alert as the absence of a CGM hypoglycemia alert within $30 \mathrm{~min}$ of the YSI reading of $70 \mathrm{mg} /$ dL. Similarly, we analyzed spurious hypoglycemic alerts (or false-positives) by defining a false alarm as a CGM alert for hypoglycemia without an estimated YSI reading of $70 \mathrm{mg} / \mathrm{dL}$ within $30 \mathrm{~min}$ of the CGM alert. This is consistent with the DirecNet consortium definitions, in which missed hypoglycemic alerts were defined as the absence of a CGM hypoglycemia alert within $30 \mathrm{~min}$ of the YSI interpolation crossing the $70 \mathrm{mg} / \mathrm{dL}$ threshold. ${ }^{19}$ Similarly, we analyzed spurious hypoglycemic alerts as a CGM alert for hypoglycemia without an estimated YSI reading of $70 \mathrm{mg} / \mathrm{dL}$ within $30 \mathrm{~min}$ of the CGM alert. We analyzed the time difference between the CGM alert indicating hypoglycemia and the estimated YSI value crossing of the $55 \mathrm{mg} / \mathrm{dL}$ threshold. The data are plotted in a cumulative distribution function showing the percentage of CGM alerts for biochemical hypoglycemia compared with the time for the estimated YSI value crossing of the threshold for cognitive impairment due to hypoglycemia.

\section{Results}

Over the measurement range of $40-400 \mathrm{mg} / \mathrm{dL}$, there were in total 2,263 matched pairs, 346 matched pairs with YSI reference data between 40 and $80 \mathrm{mg} / \mathrm{dL}$, and a total of 288 independent YSI measurements of biochemical hypoglycemia defined as $70 \mathrm{mg} / \mathrm{dL}$ or less. There were 40 temporally distinct episodes of biochemical hypoglycemia based on venous reference sample measurements made with the YSI analyzer. There were 34 episodes of more pronounced hypoglycemia based on YSI measurements crossing the cognitive impairment threshold of $55 \mathrm{mg} / \mathrm{dL}$.

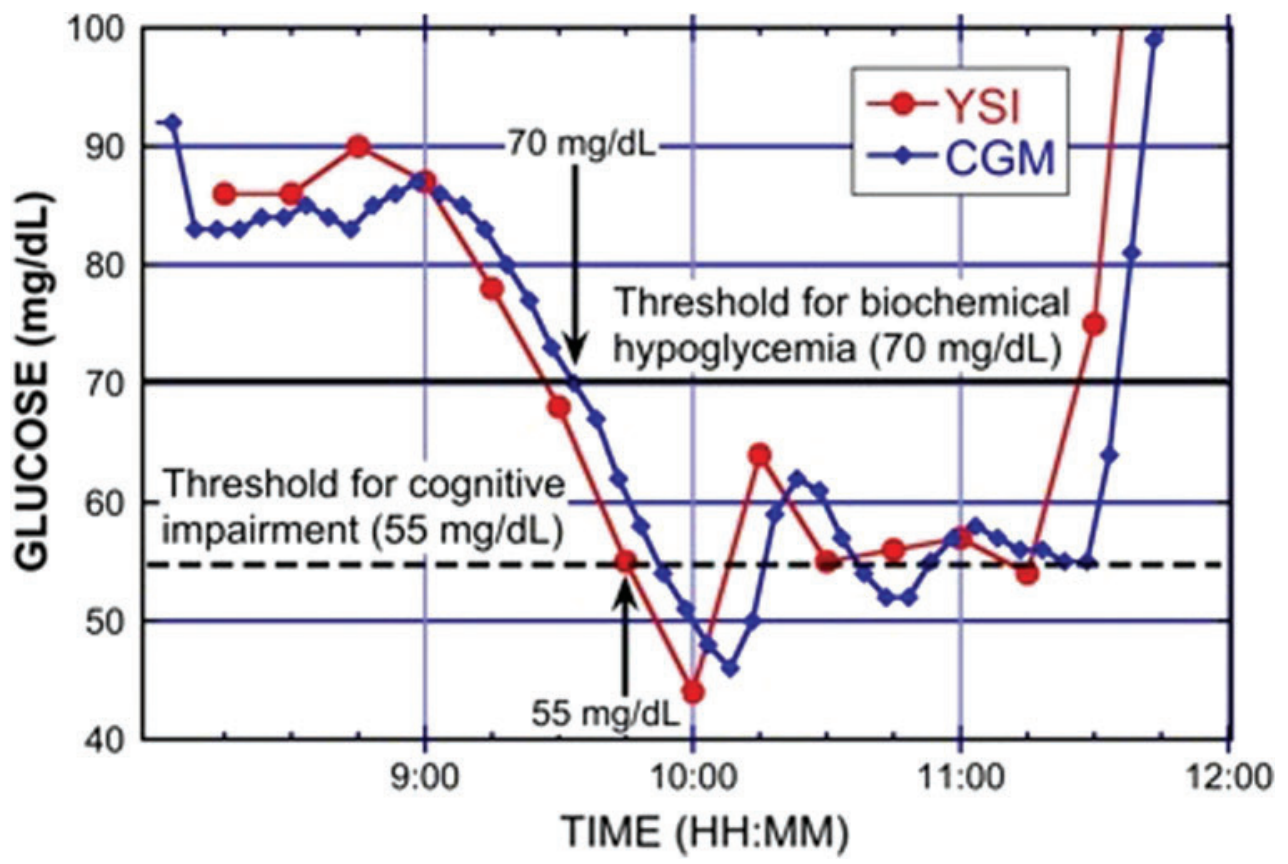

FIG. 1. Temporal trace showing descent into hypoglycemia as measured from venous samples with the YSI (circles) and interstitial glucose values from the new G4 Platinum continuous glucose monitoring (CGM) system (diamonds). In this example, the CGM provided an alert to the onset of biochemical hypoglycemia $(70 \mathrm{mg} / \mathrm{dL}) 5 \mathrm{~min}$ after the YSI analyzer value crossed the threshold and provided a warning $12 \mathrm{~min}$ before the YSI analyzer value crossed $55 \mathrm{mg} / \mathrm{dL}$, defined here as the cognitive impairment threshold. Color graphics are available at www.liebertonline.com/dia 
The pivotal clinical study of the original Dexcom G4 Platinum CGM system found improved accuracy compared with previous generations of CGM devices over the entire physiological range $(40-400 \mathrm{mg} / \mathrm{dL}) .{ }^{20}$ Over the measurement range of $40-400 \mathrm{mg} / \mathrm{dL}$, there were in total 9,093 matched pairs, 1,351 matched pairs with YSI reference data between 40 and $80 \mathrm{mg} / \mathrm{dL}$, and a total of 1,057 independent YSI measurements of biochemical hypoglycemia defined as $70 \mathrm{mg} / \mathrm{dL}$ or less. The overall mean absolute relative difference was $13 \%$, and the overall percentage of matched pairs between the CGM reading and venous reference measurement within $20 \%$ or $20 \mathrm{mg} / \mathrm{dL}$ was $82 \%$. In the hypoglycemic range defined as $70 \mathrm{mg} / \mathrm{dL}$, the mean absolute difference was $11 \mathrm{mg} / \mathrm{dL}$. Independent studies of the original G4 Platinum CGM system have found similar high levels of accuracy. ${ }^{21-23}$ The pivotal clinical study of the new G4 Platinum CGM system (software 505) reported here gave an overall mean absolute relative difference of 9\%, with $93 \%$ of all points either within $20 \%$ or $20 \mathrm{mg} / \mathrm{dL}$ of the reference measurement. ${ }^{17}$ In the hypoglycemic range defined as $70 \mathrm{mg} / \mathrm{dL}$, the mean absolute difference of the new G4 Platinum (software 505) was $6 \mathrm{mg} / \mathrm{dL}$.

Figure 2A shows an expanded Bland-Altman plot for the hypoglycemic range $(40-80 \mathrm{mg} / \mathrm{dL})$ from the original G4 Platinum data with $52 \%, 71 \%$, and $83 \%$ of all points falling within $( \pm) 10 \mathrm{mg} / \mathrm{dL}, 15 \mathrm{mg} / \mathrm{dL}$, and $20 \mathrm{mg} / \mathrm{dL}$, respectively, of the laboratory reference YSI measurement. The frequency of measurements with a given bias is color-coded in the second $y$-axis, giving a density contour map of the distribution. The expanded Bland-Altman plot for the original G4 Platinum data shows a large number of points outside of $20 \mathrm{mg} / \mathrm{dL}$ in the hypoglycemic range. Figure 2B shows an expanded Bland-Altman plot for the hypoglycemic range $(40-80 \mathrm{mg} / \mathrm{dL})$ for the new G4 Platinum (software 505) with $76 \%, 90 \%$, and $95 \%$ of all points falling within $( \pm) 10 \mathrm{mg} /$ $\mathrm{dL}, 15 \mathrm{mg} / \mathrm{dL}$, and $20 \mathrm{mg} / \mathrm{dL}$, respectively, of the laboratory reference YSI measurement.

Using the definition for a spurious alert given above of no greater than a 30-min temporal delay between the CGM hypoglycemia alert and an actual reference measurement indicating biochemical hypoglycemia, there were two instances of spurious alerts out of 41 episodes (5\%) using the $70 \mathrm{mg} / \mathrm{dL}$ alert setting and six instances using the $80 \mathrm{mg} / \mathrm{dL}$ alert setting (15\%). However, all six cases did involve actual instances of hypoglycemia. In two cases, common to both settings, the CGM device exhibited a negative bias of $20 \mathrm{mg} /$ $\mathrm{dL}$, possibly due to a calibration error, and provided a hypoglycemic alert more than $30 \mathrm{~min}$ in advance of the YSI value crossing the threshold for biochemical hypoglycemia. In the other four cases associated with the $80 \mathrm{mg} / \mathrm{dL}$ CGM hypoglycemia alert setting, the YSI value crossed the threshold for biochemical hypoglycemia more than $30 \mathrm{~min}$ after the CGM device alert not due to a calibration error but rather due to a slow descent into hypoglycemia captured equivalently on both the CGM and YSI measurements. There were five instances of missed alerts for the CGM alert setting of $70 \mathrm{mg} /$ dL $(12.5 \%)$ in which the YSI value crossed the threshold for biochemical hypoglycemia without a CGM hypoglycemic alert. There were, however, only two cases of missed alerts for the CGM hypoglycemia alert setting at $80 \mathrm{mg} / \mathrm{dL}(5 \%)$. In both these cases, the CGM system read high because of a calibration error and therefore did not alert for true hypoglycemic events.

Cumulative distribution functions for the BHAT at the CGM hypoglycemia alert settings of $70 \mathrm{mg} / \mathrm{dL}$ and $80 \mathrm{mg} / \mathrm{dL}$ are shown in Figure 3A. Cumulative distribution functions for the HCITAT are shown in Figure 3B.

In the data shown in Figure 3A, the BHAT values are primarily positive numbers, indicating that CGM often alerts after the YSI has crossed the threshold for biochemical hypoglycemia. The $70 \mathrm{mg} / \mathrm{dL}$ CGM hypoglycemic alert setting provided an alert to the patient of a hypoglycemic state within $10 \mathrm{~min}$ of actual biochemical hypoglycemia in $62 \%$ of the instances observed in the study. By contrast, the $80 \mathrm{mg} / \mathrm{dL}$ CGM hypoglycemic alert setting provided an alert to the patient of a hypoglycemic state within $10 \mathrm{~min}$ of actual biochemical hypoglycemia in $95 \%$ of the instances observed in the study. In the data shown in Figure 3B, the HCITAT values are primarily negative numbers, indicating that the alert would provide the patient with warning of hypoglycemia
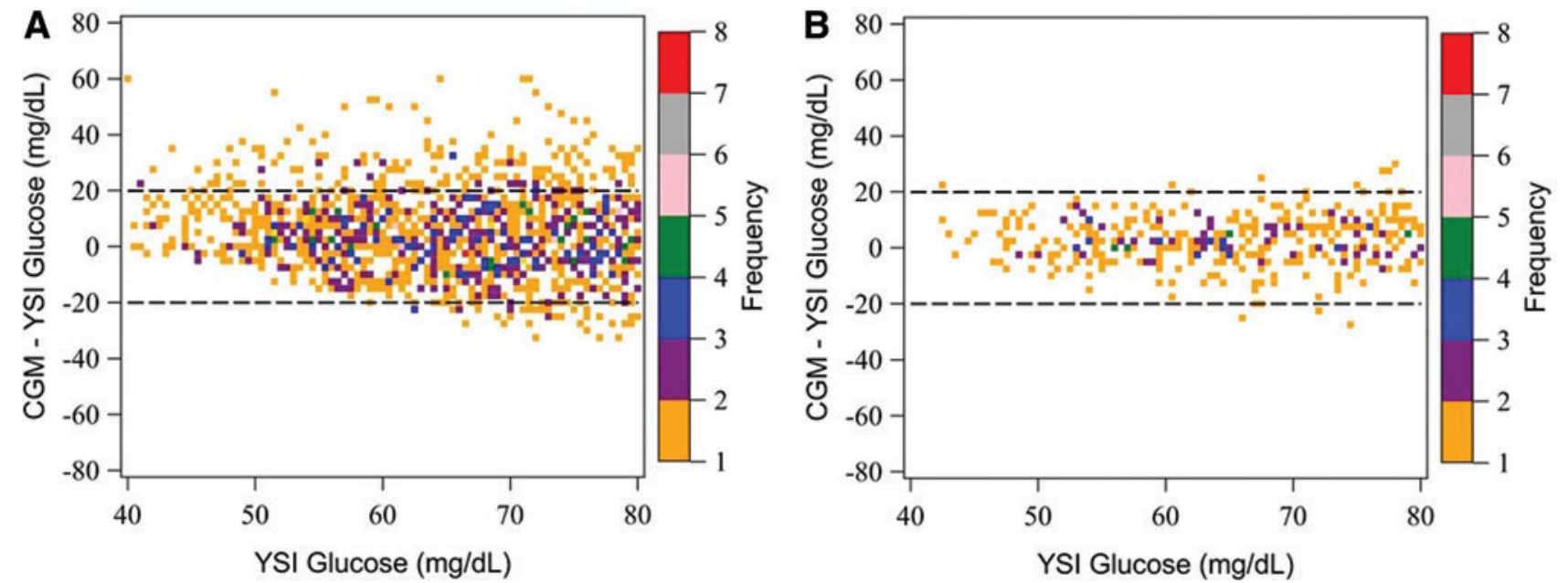

FIG. 2. Density bias (Bland-Altman) plot of (A) the original G4 Platinum continuous glucose monitoring (CGM) system showing $83 \%$ of all paired points within $\pm 20 \mathrm{mg} / \mathrm{dL}$ for $40-80 \mathrm{mg} / \mathrm{dL}$ and (B) the new G4 Platinum CGM system showing $96 \%$ of all paired points within $\pm 20 \mathrm{mg} / \mathrm{dL}$ for $40-80 \mathrm{mg} / \mathrm{dL}$. Color graphics are available at www.liebertonline.com/dia 

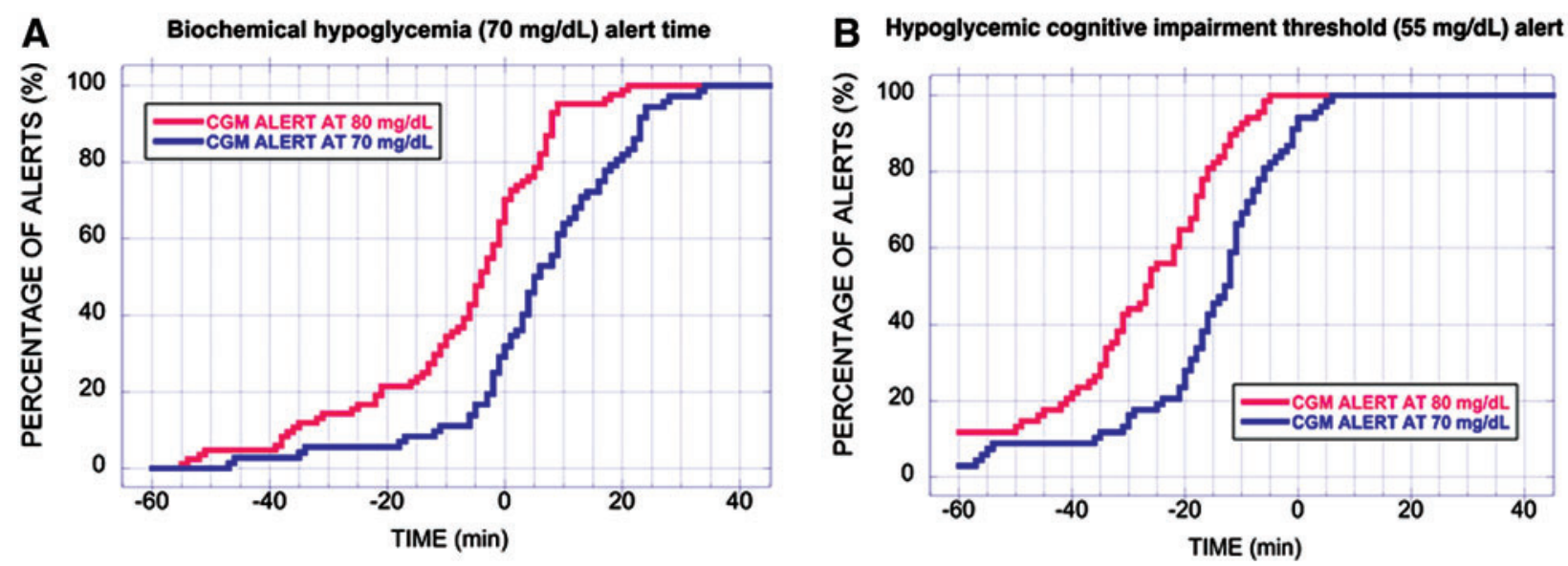

FIG. 3. Cumulative distribution functions. (A) Biochemical hypoglycemia alert time for setting of the continuous glucose monitoring (CGM) hypoglycemia alert at $70 \mathrm{mg} / \mathrm{dL}$ and $80 \mathrm{mg} / \mathrm{dL}$. The cumulative distribution function for the $80 \mathrm{mg} / \mathrm{dL}$ CGM alert setting (red) is shifted to the left, indicating earlier warning of biochemical hypoglycemia than the $70 \mathrm{mg} / \mathrm{dL}$ alert setting (blue). (B) Hypoglycemic cognitive impairment threshold alert time. The cumulative distribution function for the $80 \mathrm{mg} / \mathrm{dL} \mathrm{CGM}$ alert setting (red) is shifted to the left, indicating earlier warning of impending neuroglycopenia than the $70 \mathrm{mg} / \mathrm{dL}$ alert setting (blue). Color graphics are available at www.liebertonline.com/dia

before the YSI value has crossed the threshold for cognitive impairment and before patients experience an elevated risk for requiring the assistance of others for proper treatment of hypoglycemia. The $70 \mathrm{mg} / \mathrm{dL}$ CGM hypoglycemic alert setting provided an alert to the patient 10 min before the actual blood glucose level crossed the threshold for cognitive im-

TABle 1. Biochemical and Cognitive IMPAirment Hypoglycemia Alert Times

\begin{tabular}{ccc}
\hline & $\begin{array}{c}\text { Percentage at CGM alert } \\
\text { threshold of }\end{array}$ \\
\cline { 2 - 3 } Hypoglycemia, time (min) & $70 \mathrm{mg} / \mathrm{dL}$ & $80 \mathrm{mg} / \mathrm{dL}$ \\
\hline Biochemical (70 mg/dL) & & \\
-30 & $5 \%$ & $14 \%$ \\
-15 & $8 \%$ & $24 \%$ \\
-10 & $11 \%$ & $33 \%$ \\
-5 & $17 \%$ & $45 \%$ \\
0 & $31 \%$ & $69 \%$ \\
5 & $47 \%$ & $76 \%$ \\
10 & $64 \%$ & $95 \%$ \\
15 & $72 \%$ & $95 \%$ \\
30 & $97 \%$ & $100 \%$ \\
Cognitive impairment (55 mg/dL) & & \\
-30 & $15 \%$ & $44 \%$ \\
-15 & $44 \%$ & $82 \%$ \\
-10 & $68 \%$ & $91 \%$ \\
-5 & $82 \%$ & $100 \%$ \\
0 & $94 \%$ & $100 \%$ \\
5 & $97 \%$ & $100 \%$ \\
10 & $100 \%$ & $100 \%$ \\
\hline
\end{tabular}

The biochemical alert time is the time for the continuous glucose monitoring (CGM) value to indicate hypoglycemia compared with when the YSI analyzer value has crossed the $70 \mathrm{mg} / \mathrm{dL}$ threshold. The hypoglycemic cognitive impairment threshold alert time is the time for the CGM value to indicate hypoglycemia compared with the time when the YSI analyzer value crosses the threshold of $55 \mathrm{mg} / \mathrm{dL}$. pairment in $68 \%$ of the instances observed in the study. By contrast, the $80 \mathrm{mg} / \mathrm{dL}$ CGM hypoglycemic alert setting provided an alert to the patient $10 \mathrm{~min}$ before the actual blood glucose level crossed the threshold for cognitive impairment in $91 \%$ of the instances observed in the study. The differences in BHAT and HCITAT for the two CGM hypoglycemia alert settings are given in Table 1.

Data in the top half of Table 1 show that the CGM alert setting of $70 \mathrm{mg} / \mathrm{dL}$ provided an alert for hypoglycemia within 10 min $62 \%$ of the time that the YSI value crossed the threshold for biochemical hypoglycemia. The CGM alert setting of $80 \mathrm{mg} / \mathrm{dL}$ provided an alert for hypoglycemia within 10 min $95 \%$ of the time that the YSI value crossed the threshold. Data in the bottom half of Table 1 show that the CGM alert setting of $70 \mathrm{mg} / \mathrm{dL}$ provided an alert for hypoglycemia $15 \mathrm{~min}$ before the YSI value crossed the $55 \mathrm{mg} / \mathrm{dL}$ threshold for cognitive impairment in $45 \%$ of the cases, $10 \mathrm{~min}$ before the YSI value crossed the $55 \mathrm{mg} / \mathrm{dL}$ threshold in $68 \%$ of the cases, and 5 min before the YSI value crossed the threshold in $82 \%$ of the cases. The CGM alert setting of $80 \mathrm{mg} / \mathrm{dL}$ provided an alert for hypoglycemia $15 \mathrm{~min}$ before the YSI value crossed the $55 \mathrm{mg} / \mathrm{dL}$ threshold for cognitive impairment in $82 \%$ of the cases, $10 \mathrm{~min}$ before the YSI value crossed the $55 \mathrm{mg} / \mathrm{dL}$ threshold in $91 \%$ of the cases, and 5 min before the YSI value crossed the threshold in $100 \%$ of the cases.

\section{Discussion}

Insulin-induced hypoglycemia in type 1 diabetes remains a major problem in the treatment and management of the disease. Weinstock et al. ${ }^{24}$ reported from the T1D Exchange Registry that in all adults with available data $(n=4,973)$, there was an $11.8 \%$ incidence in the previous 12 months of seizure or coma due to hypoglycemia. In subjects with a duration of diabetes of less than 20 years, $9 \%$ have had an episode of seizure or coma in the previous 12 months, whereas for those with a duration of diabetes of over 40 years, that number increased to $19 \%$. These numbers are unacceptably high, so 
clearly new strategies to reduce the frequency of severe hypoglycemia are required. The routine use of CGM to date, however, for the prevention of hypoglycemia has been limited by persistent concerns about poor accuracy in the hypoglycemic range. The system reported here-the new Dexcom G4 Platinum CGM (software 505) - has improved accuracy in the hypoglycemic range compared with previous CGM devices. ${ }^{25,26}$

The new alert metrics proposed here, assessing the time relationship between the CGM alert and glucose crossing the biochemical hypoglycemia and cognitive impairment thresholds, are clinically relevant because they provide a measure for the real-time, instantaneous potential benefit, or lack thereof, of CGM devices to identify significant hypoglycemia from the perspective of the patient. Use of the $80 \mathrm{mg} / \mathrm{dL}$ setting for the CGM hypoglycemia alert gave substantially more time than the $70 \mathrm{mg} / \mathrm{dL}$ alert setting for the patient to take corrective action to reverse hypoglycemia at the threshold for biochemical hypoglycemia and at the threshold for cognitive impairment due to hypoglycemia. However, using a higher threshold did result in a modest increase in spurious alerts.

Because most patients are trained to use the CGM hypoglycemia alert to treat themselves for hypoglycemia with fast-acting carbohydrates, the data presented above for the new G4 Platinum CGM provide patients with the opportunity to optimize the setting of the CGM hypoglycemic alerts for their personal preferences. The $80 \mathrm{mg} / \mathrm{dL}$ setting for CGM hypoglycemic alerts resulted in 5\% missed alerts compared with $12.5 \%$ for the $70 \mathrm{mg} / \mathrm{dL}$ alert setting. Conversely, there were $15 \%$ spurious alerts at the $80 \mathrm{mg} / \mathrm{dL}$ CGM hypoglycemic alert setting compared with only $5 \%$ for the $70 \mathrm{mg} / \mathrm{dL}$ alert setting. Patients who want to minimize missed alerts might prefer the higher CGM hypoglycemic alert setting, whereas those who want to minimize spurious alerts might prefer the lower alert setting.

If the CGM can provide reliable and timely warning of hypoglycemia before patients have spent too much time below the cognitive impairment threshold of $55 \mathrm{mg} / \mathrm{dL}$, there is a greater likelihood that they can follow current ADA treatment guidelines and treat themselves with short-acting carbohydrates without requiring the assistance of others. ${ }^{27}$ In an article on severe complications of nocturnal hypoglycemia, Buckingham et al. ${ }^{28}$ noted the "likelihood that prolonged or severe hypoglycemia is needed before there is a seizure." This further underscores the clinical importance of the data presented above showing that setting the CGM hypoglycemia alert at $80 \mathrm{mg} / \mathrm{dL}$ provided advanced warning in all cases before the YSI value crossed the $55 \mathrm{mg} / \mathrm{dL}$ threshold.

The improved accuracy in the hypoglycemic range and the enhanced hypoglycemia alert performance reported here address a historic problem with CGM devices. Clinical studies are needed to determine whether this will lead to improved patient confidence and improved glycemic control in patients using this technology.

\section{Disclosure Statement}

T.A.P. has received funds for consulting from Dexcom, Tandem Diabetes Care, Insulet, and Profusa. K.N., D.P., L.C.B., and A.B. are employees of Dexcom and own stock of the company. I.B.H. has received research grants from Sanofi and Halozyme and consulting fees from Abbott and Roche.
T.A.P. was the primary author on the manuscript and was responsible for data analysis. T.A.P. is the guarantor of the contents of the article. L.C.B. assisted with data analysis and preparation of the manuscript. K.N., D.P., and A.B. were responsible for design and execution of the clinical trial and assisted with review and editing of the manuscript. A.B. and I.B.H. assisted with the development of the new metrics for hypoglycemia accuracy and with review and editing of the manuscript.

\section{References}

1. Tamborlane WV, Beck RW, Bode BW, et al.: Continuous glucose monitoring and intensive treatment of type 1 diabetes. N Engl J Med 2008;359:1464-1476.

2. Chase HP, Beck RW, Xing D, et al.: Continuous glucose monitoring in youth with type 1 diabetes: 12 -month followup of the Juvenile Diabetes Research Foundation continuous glucose monitoring randomized trial. Diabetes Technol Ther 2010;12:507-515.

3. Ruedy KJ, Tamborlane WV: The landmark JDRF continuous glucose monitoring randomized trials: a look back at the accumulated evidence. J Cardiovasc Transl Res 2012; 5:380-387.

4. Battelino T, Phillip M, Bratina N, et al.: Effect of continuous glucose monitoring on hypoglycemia in type 1 diabetes. Diabetes Care 2011;34:795-800.

5. Little SA, Leelarathna L, Barendse SM, et al.: Severe hypoglycaemia in type 1 diabetes mellitus: underlying drivers and potential strategies for successful prevention. Diabetes Metab Res Rev 2014;30:175-190.

6. Zijlstra E, Heise T, Nosek L, et al.: Continuous glucose monitoring: quality of hypoglycaemia detection. Diabetes Obes Metab 2013;15:130-135.

7. Seaquist ER, Anderson J, Childs B, et al.: Hypoglycemia and diabetes: a report of a workgroup of the American Diabetes Association and the Endocrine Society. Diabetes Care 2013;36:1384-1395.

8. American Diabetes Association Workgroup on Hypoglycemia: Defining and reporting hypoglycemia in diabetes: a report from the American Diabetes Association Workgroup on Hypoglycemia. Diabetes Care 2005;28:12451249.

9. Cryer PE: Preventing hypoglycaemia: what is the appropriate glucose alert value? Diabetologia 2009;52:35-37.

10. Klonoff DC, Bernhardt P, Ginsberg BH, et al.: Performance Metrics for Continuous Interstitial Glucose Monitoring: Approved Guideline. Wayne, PA: Clinical and Laboratory Standards Institute, 2008.

11. Cryer PE: Hypoglycemia in Diabetes: Pathophysiology, Prevalence and Prevention, 2nd ed. Alexandria, VA: American Diabetes Association, 2012.

12. Cryer PE: Hypoglycemia, functional brain failure, and brain death. J Clin Invest 2007;117:868-870.

13. Cryer P: Hypoglycemia: Pathophysiology, Diagnosis and Treatment. New York: Oxford University Press, 1997.

14. Basu A, Dube S, Slama M, et al.: Time lag of glucose from intravascular to interstitial compartment in humans. Diabetes 2013;62:4083-4087.

15. Basu A, Dube S, Veettil S, et al.: Time lag of glucose from intravascular to interstitial compartment in type 1 diabetes. J Diabetes Sci Technol 2015;9:63-68.

16. Garcia A, Rack-Gomer AL, Bhavaraju NC, et al.: Dexcom G4AP: an advanced continuous glucose monitor for the 
artificial pancreas. J Diabetes Sci Technol 2013;7:14361445.

17. Bailey TS, Chang A, Christiansen M: Clinical accuracy of a continuous glucose monitoring system with an advanced algorithm. J Diabetes Sci Technol 2015;9:209-214.

18. Bland JM, Altman DG: Statistical methods for assessing agreement between two methods of clinical measurement. Lancet 1986;1:307-310.

19. Buckingham B, Block J, Burdick J, et al.: Response to nocturnal alarms using a real-time glucose sensor. Diabetes Technol Ther 2005;7:440-447.

20. Christiansen M, Bailey T, Watkins E, et al.: A newgeneration continuous glucose monitoring system: improved accuracy and reliability compared with a previous-generation system. Diabetes Technol Ther 2013;15:881-888.

21. Damiano ER, McKeon K, El-Khatib FH, et al.: A Comparative effectiveness analysis of three continuous glucose monitors: the Navigator, G4 Platinum, and Enlite. J Diabetes Sci Technol 2014;8:699-708.

22. Kropff J, Bruttomesso D, Doll W, et al. Accuracy of two continuous glucose monitoring systems: a head-to-head comparison under clinical research centre and daily life conditions. Diabetes Obes Metab 2015;17:343-349.

23. Matuleviciene V, Joseph JI, Andelin M, et al.: A clinical trial of the accuracy and treatment experience of the Dexcom G4 sensor (Dexcom G4 system) and Enlite sensor (Guardian REAL-Time system) tested simultaneously in ambulatory patients with type 1 diabetes. Diabetes Technol Ther 2014;16:759-767.

24. Weinstock RS, Xing D, Maahs DM, et al.: Severe hypoglycemia and diabetic ketoacidosis in adults with type 1 diabetes: results from the T1D Exchange clinic registry. J Clin Endocrinol Metab 2013;98:3411-3419.

25. Medtronic: Guardian Real-TIme Continuous Glucose Monitoring System: User Guide. Northridge, CA: Medtronic, 2012.

26. Weinstein RL, Schwartz SL, Brazg RL, et al.: Accuracy of the 5-day FreeStyle Navigator Continuous Glucose Monitoring System: comparison with frequent laboratory reference measurements. Diabetes Care 2007;30:1125-1130.

27. American Diabetes Association: Standards of medical care in diabetes-2014. Diabetes Care 2014;37(Suppl 1):S14S80.

28. Buckingham B, Wilson DM, Lecher T, et al.: Duration of nocturnal hypoglycemia before seizures. Diabetes Care 2008;31:2110-2112.

Address correspondence to: Katherine Nakamura Dexcom, Inc. 6340 Sequence Drive San Diego, CA 92121

E-mail: knakamura@dexcom.com 